\title{
International Equity Markets Cross Border Trading, Or Leading?
}

Paolo Miranda, Purdue University Calumet, USA

\begin{abstract}
This paper studies the mechanisms that lead to the conclusion that one market leads another. The results of a model, based on Kyle (1985), suggest cross border trading and industry commonality as mechanisms. The data confirms the results obtained by the model showing that countries heavily engaged in cross border trading appear in variance decomposition / impulse response functions as leading other markets.
\end{abstract}

Keywords: cross border trading, international finance, leading markets

\section{INTRODUCTION}

$\mathcal{G}^{n}$

$\mathrm{n}$ the last two years, we have experienced an economic crisis that began in the U.S. but rapidly engulfed many of the world's largest economies. As a by-product of the crisis, stock markets around the world lost significant value within a short amount of time. This last fact prompted the question of information transmission across markets - what is the meaning of market A leading market B? Several papers in the literature assert that market A leads market $\mathrm{B}$, usually based on a Granger causality test or variance decomposition. Is the meaning of the assertion that the innovations in market $\mathrm{A}$ are transmitted to market $\mathrm{B}$ in a short amount of time and then priced? Or is it that factors common to the economies of A and B affect the two markets and make them appear as if one affected the other? For innovations in market A to affect market B some commonality is needed. This can be commonality in the industries traded in the markets, or cross trading, implying that innovations in one market influences the other. In relation to these questions, the results of a simple model along the lines of Kyle (1985) suggest that cross border trading influences markets when traders operating in market A impute their beliefs into the prices of market B. The results of the model also suggest that even without cross border trading industry commonality provokes trends that can be interpreted as one market leading another. Hence, the results presented in this paper suggest that the assertion of market A leads market B really refers to: "traders in market A impute their beliefs into market B", or "the commonality between the industries traded on A and B is read as leading".

Since the 1980's emerging countries gradually liberalized financial trading (Bekaert and Harvey, 1995). Liberalization prompted increased trading across borders (Arshapanali and Doukas, 1992), which would, in theory, homogenize markets (Liu, Pan, and Shieh, 1998). Despite increased cross border trading, national markets continued to differ substantially. Roll (1992) asserts that the different behavior of national stock market indices are due to differences in index construction, along with exchange rate and industry effects, with industry effects the most relevant. In spite of markets maintaining their own characteristics, interdependence has increased since 1987 (Liu, Pan, and Shieh, 1998). This increased interdependence across equity markets prompted the question how innovations in one market affect on other's, or which market leads. This question is usually answered by using VAR methods coupled with Granger causality tests to determine relative influences (for example see Eun and Shim, 1989 and Liu, Pan, and Shieh, 1998), or with error correction models in conjunction with variance decomposition (for example, see Bessler and Yang, 2003, Masish and Masish, 2002, and Chen, Firth, and Rui, 2002). Taylor and Tonks (1989), using Granger causality, find that the U.K. stock market leads the German, Dutch, and Japanese stock markets; while none of the stock markets studied influence the U.K. Phylaktis and Ravazzolo (2002) in a study encompassing the pacific basin countries plus Japan and the U.S., find that market liberalization is not enough to attract foreign investors and that the stock markets were not linked in the eighties and nineties. Dwyer and Hafer (1988), studying the stock indexes of the U.S., Japan, the U.K., and Germany, find that index levels are not correlated but changes in the indexes are. Arshanapalli and Doukas (1992) study the five biggest world indexes. 
They find that the U.S. stock market influences the stock markets in France, the U.K., and Germany; they also find that the Japanese market is not influenced by any of the other markets. From the perspective of central bankers, the measures to be taken when the home economy is influenced by foreign factors should depend, at least partially, on the transmission mechanism of such influence. If the influence of a foreign economy on the home economy is due to cross border trading, capital control might be appropriate. If, on the other hand, the transmission mechanism is industry commonality, interest rate changes might be the appropriate tool.

\section{MODEL}

The model, based on Kyle (1985), considers two markets, 1 and 2, called the "home" and "foreign" markets, respectively. Each market is endowed with an asset whose final value (liquidation value) is normally distributed with means $\mathrm{p}_{01}$ and $\mathrm{p}_{02}$, and variances $\Sigma_{1}$ and $\Sigma_{2}$ respectively. Assets are traded only in their market, so there is cross trading, but not cross listing. Both markets have uninformed traders, whose trades are normally distributed with a zero mean and standard deviations $\sigma_{1}$ and $\sigma_{2}$, respectively. Uninformed traders are not allowed to trade across markets, limiting their trades to their home market. Both markets have also informed traders, privy to the final value of the asset in their home market while their knowledge of the final value of the foreign asset is limited. The informed trader in the home market knows the liquidation value of the asset in his market, denoted by $\mathrm{v}_{1}$. He also has distorted information about the liquidation value of the asset in market 2 (the foreign market). Operating on distorted information about the foreign market is characterized as the trader in market 1 (home market) believing that the foreign asset has a value that ranges from zero $(\alpha=0)$ to the full true value of the asset in market 2 $(\alpha=1)$. Values of alpha higher than 1 are not adopted to be consistent with the profusely documented home bias, since it is difficult to make the case for traders believing foreign assets having high value and investing mostly at home. Hence, the informed trader in market 1 believes the value of the foreign asset to be $\alpha v_{2}, \alpha$ in $[0,1]$. The situation for the informed trader in market 2 is symmetric in that he knows the liquidation value of the asset in his home market while he has distorted information of the liquidation value of the asset in market 1 ; he knows $\beta \mathrm{v}_{1}, \beta$ in $[0,1]$. Informed traders are allowed to trade across markets. Both markets have auctioneers who set the price of the asset in their market as a linear function of the demand they see for the asset. The auctioneer in each market observes the sum of the demands from the home informed trader, foreign informed trader, and home noise trader; but he cannot distinguish between them. The informed traders' demands are a linear function of their information, hence the demands of the home informed trader can be expressed as:

$$
\left[\begin{array}{l}
x_{11} \\
x_{12}
\end{array}\right]=\left[\begin{array}{l}
c_{11} \\
c_{12}
\end{array}\right]+\left[\begin{array}{cc}
d_{11} & 0 \\
0 & d_{12}
\end{array}\right]\left[\begin{array}{c}
v_{1} \\
\alpha v_{2}
\end{array}\right]
$$

Equally, the demands of the foreign informed trader can be expressed as:

$$
\left[\begin{array}{l}
x_{21} \\
x_{22}
\end{array}\right]=\left[\begin{array}{l}
c_{21} \\
c_{22}
\end{array}\right]+\left[\begin{array}{cc}
d_{21} & 0 \\
0 & d_{22}
\end{array}\right]\left[\begin{array}{c}
\beta v_{1} \\
v_{2}
\end{array}\right]
$$

Where $x_{i j}$ represents the demand of informed trader from market $i$ in market $j$; hence, $x_{12}$ represents the demand of the home informed trader in the foreign market. The constants $c_{i j}$ represent the minimum level of demand for the informed trader in the home market, corresponding to the belief of the liquidation value of both assets being zero. The constants $\mathrm{d}_{\mathrm{ij}}$ represent the change in the demand for asset $\mathrm{j}$ by trader $\mathrm{i}$ if the value of asset $\mathrm{j}$ changes.

In both markets, the market makers observe the demand for the asset and set the price as a linear function of demand. Hence, the prices in markets one and two are given by:

$p_{1}=a_{1}+b_{1}\left(x_{11}+x_{21}+\tilde{u}_{1}\right)$ 
$p_{2}=a_{2}+b_{2}\left(x_{21}+x_{22}+\tilde{u}_{2}\right)$

Where $a_{i}$ are constants reflecting the minimum price of the assets, as set by the auctioneers when the demand for them is zero; and $b_{i}$ reflects the change in price set by the auctioneer when he sees a change in the asset's demands.

Both informed traders choose their total demand to maximize their expected utility conditional on the information they possess. The home informed trader chooses $\mathrm{x}_{11}$ and $\mathrm{x}_{12}$ to maximize:

$E\left[\left(\tilde{v}_{1}-p_{1}\right) x_{11}+\left(\tilde{v}_{2}-p_{2}\right) x_{12} \mid v_{1}, \alpha v_{2}\right]$

The foreign informed trader chooses $\mathrm{x}_{21}$ and $\mathrm{x}_{22}$ to maximize:

$E\left[\left(\tilde{v}_{1}-p_{1}\right) x_{21}+\left(\tilde{v}_{2}-p_{2}\right) x_{22} \mid \beta v_{1}, v_{2}\right]$

Market efficiency dictates that the price in each market be the expected value of the asset given the information available to the market maker. In this case, this is simply the total demand for the asset. Hence, the price for the asset in the home market can be written as:

$p_{1}=E\left[v_{1} \mid x_{11}+x_{21}+\tilde{u}_{1}=y_{1}\right]$

And the price of the asset in the foreign market can be written as:

$p_{2}=E\left[v_{2} \mid x_{12}+x_{22}+\tilde{u}_{2}=y_{2}\right]$

Combining the first order conditions from the maximization of equations (5) and (6) we have four equations and four unknowns $\left(\mathrm{x}_{11}, \mathrm{x}_{12}, \mathrm{x}_{21}, \mathrm{x}_{22}\right)$. Solving the four equations simultaneously we get results that depend on the parameters $\mathrm{a}_{1}, \mathrm{a}_{2}, \mathrm{~b}_{1}, \mathrm{~b}_{2}$.

Developing equations (7) and (8) and replacing the demands from equations (1) and (2), we can solve for $b_{1}$ and $\mathrm{b}_{2}$ obtaining:

$b_{1}=\frac{1}{3} \frac{\sqrt{\Sigma_{1}}}{\sigma_{1}} \sqrt{2-\beta^{2}+6 \beta^{3}-4 \beta^{4}}$

And for $b_{2}$ :

$b_{2}=\frac{1}{3} \frac{\sqrt{\Sigma_{2}}}{\sigma_{2}} \sqrt{2-\alpha^{2}+6 \alpha^{3}-4 \alpha^{4}}$

Since $b_{1}$ increases with $\beta$, equation (9) suggests that the price of the asset in the home market is greater the closer is the information possessed by the foreign informed trader to the true liquidation value of the asset in the home market. Also, equation (9) shows that the price of the asset in home market is lower the higher the variance of noise trading. Similar conclusions apply to the foreign market.

Once $b_{1}$ and $b_{2}$ are obtained, we can calculate the demand of each informed trader in each market. The demand of the home informed trader at home $\left(\mathrm{x}_{11}\right)$ and in the foreign market $\left(\mathrm{x}_{12}\right)$ are: 


$$
x_{11}=\frac{\sigma_{1}}{\sqrt{\Sigma_{1}}} \frac{\left[v_{1}(2-\beta)-p_{01}\right]}{\sqrt{2-\beta^{2}+6 \beta^{8}-4 \beta^{4}}}, x_{12}=\frac{\sigma_{2}}{\sqrt{\Sigma_{2}}} \frac{\left[v_{2}(2 \alpha-1)-p_{02}\right]}{\sqrt{2-\alpha^{2}+6 \alpha^{3}-4 \alpha^{4}}}
$$

The demand of the foreign informed trader in his market $\left(\mathrm{x}_{22}\right)$, and in the home market $\left(\mathrm{x}_{21}\right)$ are:

$x_{22}=\frac{\sigma_{2}}{\sqrt{\Sigma_{2}}} \frac{\left[v_{2}(2-\alpha)-p_{02}\right]}{\sqrt{2-\alpha^{2}+6 \alpha^{3}-4 \alpha^{4}}}, x_{21}=\frac{\sigma_{1}}{\sqrt{\Sigma_{1}}} \frac{\left[v_{1}(2 \beta-1)-p_{01}\right]}{\sqrt{2-\beta^{2}+6 \beta^{3}-4 \beta^{4}}}$,

The results for the demands of the traders show that the information possessed by foreign traders affects home traders. For example, if the foreign trader (in market two) knows the liquidation value of the asset in market 1 to be $\mathrm{v}_{1}$ (equivalent to $\beta=1$ ), he will buy the same amount of the asset as the home trader $\left(\mathrm{x}_{11}=\mathrm{x}_{21}\right)$. Also, home informed traders will not trade in the foreign market if they believe the value of the asset to be the average between the liquidation value of the foreign asset and the price at $t=0$, this is obtained by solving for the condition that makes $\mathrm{x}_{12}$ equal to zero. The result for the demand of home informed trader in the foreign market $\left(\mathrm{x}_{12}\right)$ shows that noise trading in the foreign market attracts informed traders from abroad because it allows them to hide their trades. To the contrary, a very volatile foreign asset deters home informed traders from trading abroad. The home informed trader will trade less in the home market the more accurate is the information possessed by the foreign trader, because the foreign trader will bid up the price of the home asset. The conditional variance allows us to study the effect of new information about the asset in the home market on the price of the foreign asset, the following is the variance of the foreign asset price conditional on the value of the home asset $\left(\operatorname{var}\left[\mathrm{p}_{2} \mid \mathrm{v}_{1}\right]\right)$ :

$\operatorname{var}\left[p_{2} \mid v_{1}\right]=\frac{2}{3}\left[\alpha^{2}-\alpha+1\right] \Sigma_{2}-\frac{4\left[\alpha^{2}-\alpha+1\right]}{2-\alpha^{2}+6 \alpha^{8}-4 \alpha^{4}} \frac{\sigma_{2}^{2}}{\Sigma_{2}} \Sigma_{12}^{2}$

where $\Sigma_{12}$ is the covariance between the assets in the two markets at the beginning of trading.

Equation (11) suggests that the home market affects the foreign market by two different mechanisms. The first term shows that home traders affect the variance of the foreign price via cross border trading. It can also be seen that the variance of the foreign price will not be zero even in the no trade condition. The second term shows that information that affects the assets in both markets, reflected in the correlation between them, will affect the price in the foreign market. Even if the no trading condition holds, the covariance between the assets will influence both the home and foreign markets; suggesting that what is interpreted as influence of one market over another could be the result of information affecting common industries. The unconditional variance for the price in the foreign market is given by

$\operatorname{var}\left[p_{2}\right]=\frac{2}{3}\left[\alpha^{2}-\alpha+1\right] \Sigma_{2}$

Equation (12) highlights the mechanism by which the information held by home traders $(\alpha)$ influences the unconditional variance of the price of the foreign asset. If the home trader information is that the liquidation value of the foreign asset is zero $(\alpha=0)$, he will short the foreign asset $\left(\mathrm{x}_{12}<0\right)$, driving down the price and increasing the volatility. The variance of the foreign asset price is a convex function of $\alpha$, indicating that in the zero trading condition, where $\alpha$ is between zero and one, the variance of the price will be less than any of the extremes. Hence, if the home trader decides not to trade in the foreign market, the unconditional variance of the foreign asset price will diminish with respect to the case in which he trades.

Also, to assess under what conditions the price in the home market affects the variance of the price in the foreign market, the conditional variance of the foreign price given the price of the home market asset is used. The conditional variance can be expressed as: 
$\operatorname{var}\left[p_{2} \mid p_{1}\right]=\frac{4}{9}\left[\beta^{2}-\beta+1\right]\left[\alpha^{2}-\alpha+1\right] \Sigma_{12}$

To compare, Equation (11) shows that the variance of the foreign asset price conditional on the home asset value depends on: (i) how accurate is the information held by the home trader about the foreign asset (represented by $\alpha$ ), (ii) the volatility of the true value of the foreign asset $\left(\Sigma_{2}\right)$, and (iii) on the covariance between the assets $\left(\Sigma_{12}\right)$. Equation (13) shows that the variance of the foreign asset price conditional on the home asset price depends on the accuracy of the information held by both traders and on the covariance between the underlying assets in both markets. Hence, if the covariance between the liquidation value of the assets is zero, there will be no effect of the home price on the foreign price volatility.

Overall, the results from the model suggest that the effects on prices of cross trading activity could be interpreted as one market leading another in a variance decomposition study. The results also suggest that prices in one market will not influence another market unless some common factor is present like common industries or resources.

\section{EMPIRICS}

The model presented in the last section suggests that both cross border investment and industry commonality among countries could result in variance decomposition / impulse response functions studies finding that a market leads another. This section assesses whether cross border trading and industry commonality can explain the assertion that a market leads another. As a first step, a variance decomposition / impulse response function study is performed using the stock markets of the U.S., the U.K., Brazil, Argentina, France, Germany, Japan, Canada, and Switzerland to find out which market leads which according to the standard interpretation of those results. The results of the first step are then compared with the level of foreign portfolio investment and with the proportion of different industries in the GDP to study whether the predictions of the model are supported by the data. The expectation, based on the model, is that a country with high levels of portfolio investment should appear as leading other markets, the same with a high level of industry commonality.

Weekly data on stock market indices between January 2001 to December 2007 from the U.S., the U.K., Brazil, Argentina, France, Germany, Japan, Canada, and Switzerland are taken from Yahoo Finance. Weekly data is preferred to daily data because of the non-synchronous trading induced correlation in daily data documented by Lo and MacKinlay (1999). The Coordinated Portfolio Investment Survey Data from the International Monetary Fund, covering the years 2001 to 2007, is used to assess the degree of cross border portfolio investment between the countries used in the study. The weekly exchange rates are obtained from OANDA, the ask price is used to express the indexes in dollar terms. The market capitalization of the stock exchanges for the years 2001 to 2007 is obtained from the World Federation of Exchanges. The decomposition of the GDP into different industries is obtained from the United Nations Statistical Database. The countries chosen for this study account, on average, for $62 \%$ of the world total portfolio investment between the years 2001 to 2007.

In agreement with the results presented in this paper, Arshanapalli and Doukas (1992) report that the U.S. market influences the U.K., German, and French markets but has little influence on the Japanese market. The results presented in this paper also agree with Bessler and Yang (2003) findings that the U.S. market consistently influences other major stock markets, and that the Japanese market is one of the least subject to influences from other major markets. Further, the results presented in this paper also agree with Chen, Firth, and Rui (2002) in the sense that the Brazilian stock market influences the Argentinean stock market. In agreement with Masish and Masish (2002), the impulse response functions show that the Japanese market influences the U.S., Canadian, and U.K. markets, but the percentage is very low compared with the influence exerted by other markets, of the order of $1 \%$ for the Canadian market and $0.5 \%$ for the U.K. and U.S. markets.

The model presented in the first part of this paper suggests that the better the information possessed by home informed traders (higher $\alpha$ ) about assets in a foreign market, the more they will invest in a foreign country and the higher the impact they will have on the variation of foreign stocks. Table 1 presents the foreign portfolio investment by country. 
The main foreign portfolio investor between all the countries in this study is the U.S., accounting for $48 \%$ on average of the joint portfolio investment between the countries considered in this study, when compared with the world, this number is $30 \%$. Following the U.S. is the U.K., accounting for $16 \%$ on average of the joint portfolio investment between the countries considered in this study, compared with the world this number is $9.8 \%$. Consistent with the U.S. level of foreign portfolio investment, Table 2 presents the error variance decomposition results showing that the S\&P 500 explains between 10 and 50 percent of non U.S. stocks' return variation. Figure 1 shows the impulse response function when the impulse originates in the S\&P 500. It can be seen that most of the movement in the S\&P 500 is caused by itself suggesting that the U.S. market is almost independent from other markets. It can also be seen that the S\&P 500 influences all the markets considered in this study, specially the Canadian and European markets.

Table 1: Foreign portfolio investment for countries used in this study for the years 2001-2007

\begin{tabular}{|l|c|c|c|c|c|c|c|}
\hline \multicolumn{1}{|c|}{ Country } & $\mathbf{2 0 0 1}$ & $\mathbf{2 0 0 2}$ & $\mathbf{2 0 0 3}$ & $\mathbf{2 0 0 4}$ & $\mathbf{2 0 0 5}$ & $\mathbf{2 0 0 6}$ & $\mathbf{2 0 0 7}$ \\
\hline Argentina & 6,816 & 6,765 & 7,466 & 8,461 & 9,560 & 11,526 & 14,898 \\
\hline Brazil & 2,987 & 2,375 & 2,486 & 2,235 & 2,792 & 3,734 & 6,547 \\
\hline Canada & 230,791 & 203,204 & 276,787 & 319,419 & 382,726 & 500,818 & 611,076 \\
\hline France & 201,755 & 200,093 & 340,248 & 446,499 & 529,292 & 709,168 & 859,248 \\
\hline Germany & 381,186 & 331,229 & 440,817 & 523,833 & 525,638 & 883,500 & 981,272 \\
\hline Japan & 227,351 & 210,820 & 274,457 & 364,693 & 408,570 & 510,419 & 573,470 \\
\hline Switzerland & 247,411 & 218,242 & 293,657 & 339,467 & 357,345 & 421,500 & 511,285 \\
\hline United Kingdom & 558,337 & 493,030 & 663,876 & 879,342 & $1,068,374$ & $1,366,485$ & $1,541,435$ \\
\hline United States & $1,612,667$ & $1,385,359$ & $2,080,302$ & $2,560,418$ & $3,317,705$ & $4,328,962$ & $5,247,983$ \\
\hline total countries in study & $3,469,301$ & $3,051,117$ & $4,380,096$ & $5,444,367$ & $6,602,002$ & $8,736,112$ & $10,347,214$ \\
\hline total world & $5,200,066$ & $4,796,317$ & $6,949,116$ & $8,709,029$ & $10,572,792$ & $14,151,008$ & $17,130,098$ \\
\hline countries in study/world & 0.667 & 0.636 & 0.630 & 0.625 & 0.624 & 0.617 & 0.604 \\
\hline
\end{tabular}

Foreign portfolio investment between the years 2001-2007 in million dollars. Portfolio investment is defined in the fifth edition of the Balance of Payments Manual (BPM5) issued by the IMF.

It is worth mentioning that the yearly U.S. portfolio investment in Canada between 2001 and 2007 has been, on average, 204,148 million dollars, corresponding to $16 \%$ of the Canadian market capitalization. During the same period, the average aggregated yearly investment in German, Swiss, and French stocks have been around 509,845 million dollars, corresponding to approximately $15 \%$ of these countries combined market capitalization. The U.S. average yearly portfolio investment in the U.K. has been 493,476 million dollars, corresponding to approximately $17 \%$ of the market capitalization. As a contrast, average yearly U.S. portfolio investment in Argentina has been around 1,145 million dollars, corresponding to $2.8 \%$ of the Argentinean market capitalization. These differences in portfolio investment could explain the differences in the impulse response functions and variance decomposition results.

Table 2: Response of various markets to variations in the S\&P 500

\begin{tabular}{|c|c|c|c|c|c|c|c|c|c|}
\hline period & sp500 & ftse & bovespa & merval & dax & cac & smi & tsx & nikkei \\
\hline 0 & 0 & 0 & 0 & 0 & 0 & 0 & 0 & 0 & 0 \\
\hline 1 & 1.000 & 0.369 & 0.236 & 0.097 & 0.501 & 0.441 & 0.326 & 0.452 & 0.104 \\
\hline 2 & 0.964 & 0.387 & 0.255 & 0.113 & 0.536 & 0.445 & 0.359 & 0.518 & 0.169 \\
\hline 3 & 0.964 & 0.366 & 0.235 & 0.098 & 0.526 & 0.425 & 0.368 & 0.513 & 0.152 \\
\hline 4 & 0.960 & 0.378 & 0.248 & 0.107 & 0.540 & 0.434 & 0.376 & 0.537 & 0.168 \\
\hline 5 & 0.964 & 0.373 & 0.245 & 0.104 & 0.541 & 0.430 & 0.381 & 0.541 & 0.168 \\
\hline 6 & 0.964 & 0.377 & 0.247 & 0.106 & 0.546 & 0.432 & 0.387 & 0.551 & 0.172 \\
\hline 7 & 0.965 & 0.376 & 0.247 & 0.105 & 0.548 & 0.431 & 0.389 & 0.555 & 0.174 \\
\hline 8 & 0.966 & 0.377 & 0.248 & 0.106 & 0.550 & 0.432 & 0.392 & 0.560 & 0.176 \\
\hline 9 & 0.966 & 0.377 & 0.248 & 0.106 & 0.551 & 0.431 & 0.394 & 0.563 & 0.177 \\
\hline 10 & 0.967 & 0.377 & 0.248 & 0.106 & 0.553 & 0.432 & 0.396 & 0.566 & 0.178 \\
\hline
\end{tabular}

Impulse response function that shows the response of the return variation on various indices to changes in the S\&P 500, the response is measured over 10 periods. The years used to obtain the impulse response function are between 2001 and 2007 , frequency is weekly. The indexes are sp500:U.S., ftse:U.K.., bovespa: Brazil, merval: Argentina, dax: Germany, cac: France, smi: Switzerland, tsx: Canada, Nikkei: Japan 
Figure 1: Impulse response function for several indexes, the impulse is the S\&P 500

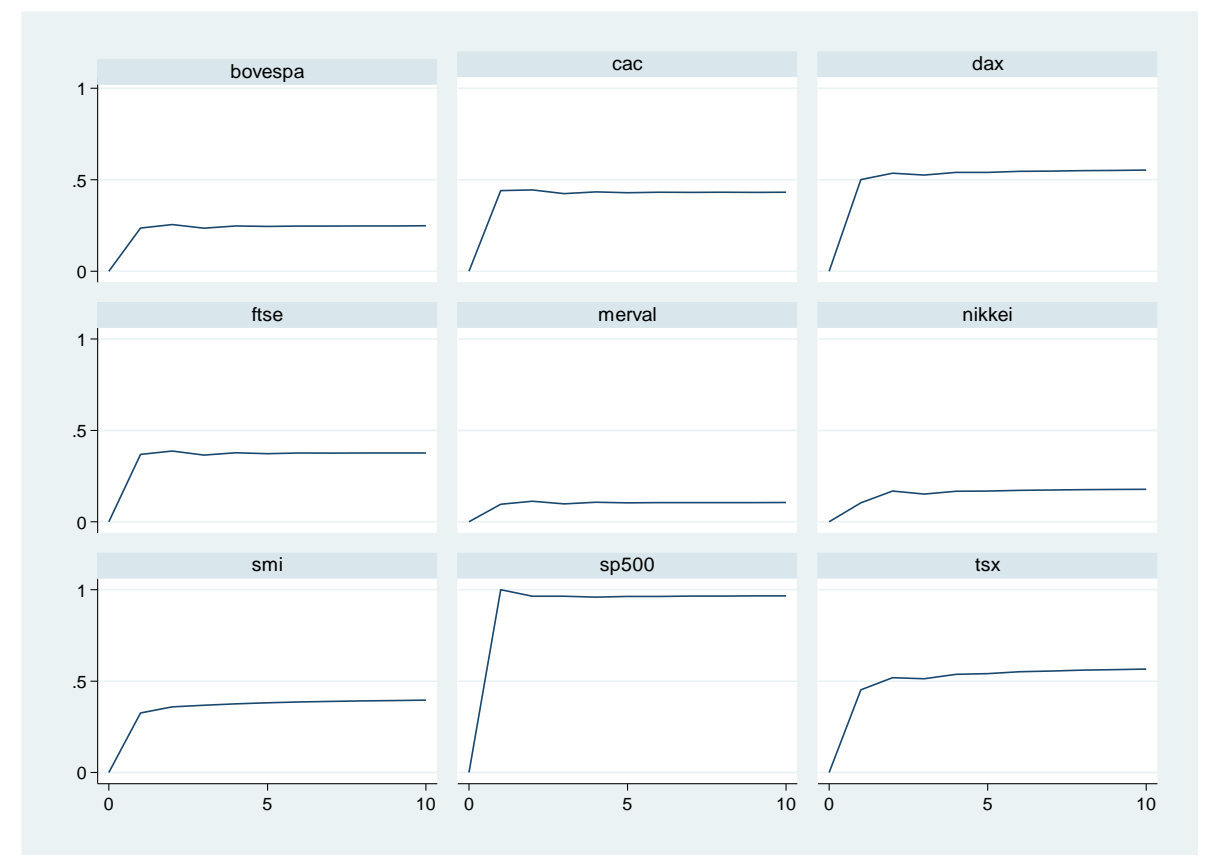

Impulse response functions for several markets considered in this study, the number of periods is ten, the frequency is weekly. The indexes are sp500:U.S., ftse:U.K.., bovespa: Brazil, merval: Argentina, dax: Germany, cac: France, smi: Switzerland, tsx: Canada, Nikkei: Japan

Table 3 shows that, consistent with the level of U.K. foreign portfolio investment, the influence of the FTSE 100 on non U.K. stock variation ranks from 0.2 to 24 percent, with the biggest influence localized in Europe. The average yearly portfolio investment by the U.K. in the countries considered in this study between the years 2001 and 2007 is 511,260 million dollars, of which 237,185 million correspond to investment on the U.S. and 161,160 million dollars to combined investment in Switzerland, Germany, and France. The U.K. portfolio investment accounts for approximately $4 \%$ of the market capitalization of the Swiss, German, and French markets; as for the U.S., U.K. portfolio investment correspond to only $1.9 \%$ of the market capitalization.

Table 3: Response of various markets to variations in the FTSE 100

\begin{tabular}{|c|c|c|c|c|c|c|c|c|c|}
\hline period & Sp500 & ftse & bovespa & merval & dax & cac & smi & tsx & nikkei \\
\hline 0 & 0 & 0 & 0 & 0 & 0 & 0 & 0 & 0 & 0 \\
\hline 1 & 0.000 & 0.631 & 0.021 & 0.014 & 0.210 & 0.304 & 0.287 & 0.026 & 0.032 \\
\hline 2 & 0.003 & 0.599 & 0.020 & 0.011 & 0.190 & 0.297 & 0.249 & 0.024 & 0.033 \\
\hline 3 & 0.002 & 0.624 & 0.026 & 0.015 & 0.195 & 0.314 & 0.253 & 0.023 & 0.032 \\
\hline 4 & 0.003 & 0.610 & 0.024 & 0.014 & 0.190 & 0.310 & 0.247 & 0.023 & 0.034 \\
\hline 5 & 0.003 & 0.616 & 0.025 & 0.015 & 0.191 & 0.313 & 0.247 & 0.023 & 0.034 \\
\hline 6 & 0.003 & 0.613 & 0.024 & 0.014 & 0.189 & 0.313 & 0.243 & 0.023 & 0.034 \\
\hline 7 & 0.003 & 0.615 & 0.025 & 0.014 & 0.188 & 0.315 & 0.243 & 0.023 & 0.035 \\
\hline 8 & 0.003 & 0.614 & 0.025 & 0.014 & 0.188 & 0.315 & 0.242 & 0.023 & 0.035 \\
\hline 9 & 0.003 & 0.614 & 0.025 & 0.014 & 0.187 & 0.316 & 0.241 & 0.023 & 0.035 \\
\hline 10 & 0.003 & 0.614 & 0.025 & 0.014 & 0.187 & 0.316 & 0.240 & 0.023 & 0.035 \\
\hline
\end{tabular}

Variance decomposition that shows the response of the return on various indices to changes in the FTSE 100, the response is measured over 10 periods. The years used to obtain the impulse response function are between 2001 and 2007, frequency is weekly. The indexes are sp500:U.S., ftse:U.K.., bovespa: Brazil, merval: Argentina, dax: Germany, cac: France, smi: Switzerland, tsx: Canada, Nikkei: Japan 
These differences in portfolio investments are reflected in the impulse response functions, supporting the basic idea of the model, namely that cross border investment may be read as one market leading another. Figure 2 presents the impulse response function when the impulse originates in the FTSE 100. Even though all the markets react, to a different degree, to the FTSE 100, the biggest reactions are from European markets (DAX, CAC40, SMI) and there is almost no reaction from the S\&P 500 .

Figure 2: Impulse response functions, impulse is FTSE 100

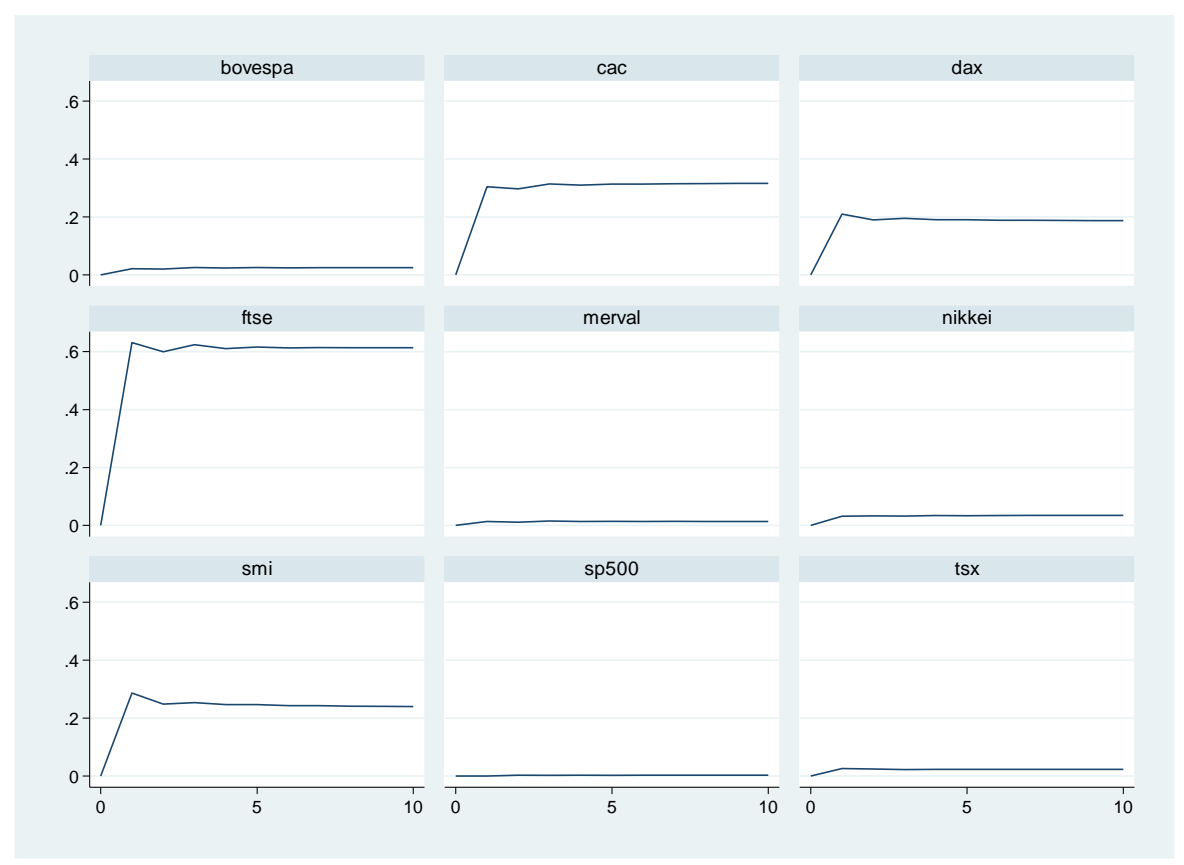

Impulse response functions for several markets considered in this study, the number of periods is ten, the frequency is weekly. The indexes are sp500:U.S., ftse:U.K.., bovespa: Brazil, merval: Argentina, dax: Germany, cac: France, smi: Switzerland, tsx: Canada, Nikkei: Japan

In contrast, Argentina and Brazil account for 0.16 and 0.05 percent of total portfolio investment, being the two lowest in the group. Consistent with the Brazilian share of total portfolio investment compared with the U.S. and U.K., Table 4 shows that the BOVESPA does not explain more than 5.9\% of the variation in non-Brazilian stock returns. The average yearly Brazilian portfolio investment in Argentina is 80 million dollars, corresponding to $0.19 \%$ of the Argentinean market capitalization. As a contrast, average yearly Brazilian portfolio investment in the U.S. is 721 million dollars, corresponding to $0.006 \%$ of the U.S. market capitalization. Consistent with the proportion of the market cap invested, the variation in the BOVESPA affects MERVAL more than it affects the S\&P 500. Figure 3 shows that the biggest reaction to an impulse originated in the Brazilian market is in the Argentinean market, and that the S\&P 500 and most of the other markets shows no reaction to an impulse originated in the BOVESPA index. This can be caused, as explained by the model, by the very low Brazilian portfolio investment as proportion of the non Brazilian market cap.

Table 5 shows that the variation in the Argentinean MERVAL does not explain more than $0.36 \%$ of the variation in non-Argentinean stock returns. The highest Argentinean portfolio investment between the countries studied is in the U.S., with a yearly average of 1,038 million dollars, followed by investment in Brazil with an average of 690 million dollars; as a proportion of the market capitalization this numbers are $0.05 \%$ and $0.14 \%$ respectively. The low influence of the MERVAL in other indexes variation is consistent with Argentinean portfolio investment being a low proportion of the foreign market capitalization. Figure 4 shows the impulse response function of the markets considered in this study when the impulse is the MERVAL. Given the low Argentinean 
portfolio investment as a proportion of the foreign market capitalization, it is consistent with the model that foreign markets will react very little to an impulse originated in MERVAL. Figure 4 shows that there is almost no response from foreign markets to an impulse originated in MERVAL.

Table 4: Response of various markets to variations in the BOVESPA index

\begin{tabular}{|c|c|c|c|c|c|c|c|c|c|}
\hline period & sp500 & ftse & bovespa & merval & dax & cac & smi & tsx & nikkei \\
\hline 0 & 0 & 0 & 0 & 0 & 0 & 0 & 0 & 0.000 & 0.000 \\
\hline 1 & 0.000 & 0.000 & 0.743 & 0.059 & 0.003 & 0.000 & 0.002 & 0.032 & 0.027 \\
\hline 2 & 0.015 & 0.0007 & 0.717 & 0.057 & 0.003 & 0.001 & 0.002 & 0.026 & 0.031 \\
\hline 3 & 0.011 & 0.0008 & 0.722 & 0.053 & 0.003 & 0.001 & 0.001 & 0.031 & 0.029 \\
\hline 4 & 0.014 & 0.0008 & 0.710 & 0.053 & 0.003 & 0.001 & 0.002 & 0.028 & 0.031 \\
\hline 5 & 0.013 & 0.0009 & 0.713 & 0.052 & 0.003 & 0.001 & 0.001 & 0.028 & 0.031 \\
\hline 6 & 0.013 & 0.0009 & 0.710 & 0.052 & 0.003 & 0.001 & 0.001 & 0.027 & 0.031 \\
\hline 7 & 0.013 & 0.0009 & 0.709 & 0.052 & 0.003 & 0.002 & 0.001 & 0.027 & 0.031 \\
\hline 8 & 0.013 & 0.0009 & 0.708 & 0.052 & 0.003 & 0.002 & 0.001 & 0.027 & 0.032 \\
\hline 9 & 0.013 & 0.0010 & 0.708 & 0.051 & 0.003 & 0.002 & 0.001 & 0.026 & 0.032 \\
\hline 10 & 0.013 & 0.0010 & 0.707 & 0.051 & 0.003 & 0.002 & 0.001 & 0.026 & 0.032 \\
\hline
\end{tabular}

Variance decomposition that shows the response of the return on various indices to changes in the BOVESPA index, the response is measured over 10 periods. The years used to obtain the impulse response function are between 2001 and 2007 , frequency is weekly. The indexes are sp500:U.S., ftse:U.K.., bovespa: Brazil, merval: Argentina, dax: Germany, cac: France, smi: Switzerland, tsx: Canada, Nikkei: Japan

Figure 3: Impulse response function, the impulse is BOVESPA

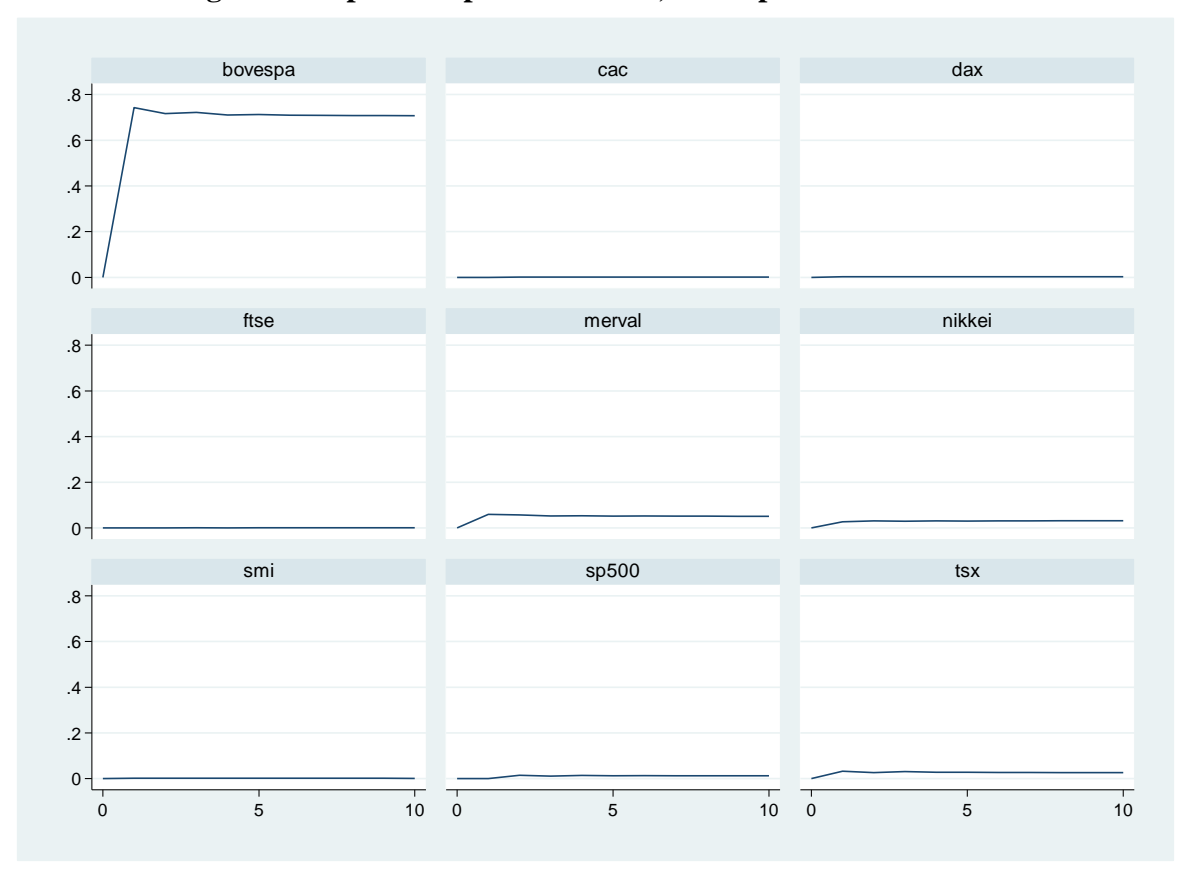

Impulse response functions for several markets considered in this study, the number of periods is ten, the frequency is weekly. The indexes are sp500:U.S., ftse:U.K.., bovespa: Brazil, merval: Argentina, dax: Germany, cac: France, smi: Switzerland, tsx: Canada, Nikkei: Japan

Germany, France, and Switzerland account for 10, 8, and 6 percent of the portfolio investment respectively across the countries studied. Consistent with their proportion of the total portfolio investment, the DAX accounts for between 0 and 12 percent of foreign stock return variation, CAC accounts for between 0 and 10 percent of foreign 
stock variation while SMI accounts for between 0 and 6 percent of the variation of foreign stock returns. The only country for which the level of portfolio investment does not match the influence on foreign stock variation is Japan. Japan is responsible for around $6 \%$ of the portfolio investment between the countries considered in this study and approximately $4 \%$ of the world portfolio investment.

Table 5: Response of various markets to variations in the MERVAL index

\begin{tabular}{|c|c|c|c|c|c|c|c|c|c|}
\hline period & sp500 & ftse & bovespa & merval & dax & rtcac & rtsmi & rttsx & nikkei \\
\hline 0 & 0 & 0 & 0 & 0 & 0 & 0 & 0 & 0 & 0 \\
\hline 1 & 0.00000 & 0.00000 & 0.00000 & 0.83007 & 0.00018 & 0.00127 & 0.00012 & 0.00213 & 0.00084 \\
\hline 2 & 0.00011 & 0.00016 & 0.00000 & 0.81520 & 0.00110 & 0.00451 & 0.00181 & 0.00215 & 0.00068 \\
\hline 3 & 0.00008 & 0.00012 & 0.00002 & 0.82569 & 0.00079 & 0.00351 & 0.00152 & 0.00346 & 0.00052 \\
\hline 4 & 0.00007 & 0.00024 & 0.00009 & 0.81806 & 0.00081 & 0.00402 & 0.00168 & 0.00318 & 0.00055 \\
\hline 5 & 0.00009 & 0.00020 & 0.00008 & 0.82264 & 0.00071 & 0.00388 & 0.00155 & 0.00347 & 0.00050 \\
\hline 6 & 0.00008 & 0.00021 & 0.00010 & 0.82127 & 0.00070 & 0.00401 & 0.00164 & 0.00343 & 0.00047 \\
\hline 7 & 0.00008 & 0.00019 & 0.00009 & 0.82257 & 0.00066 & 0.00396 & 0.00160 & 0.00353 & 0.00046 \\
\hline 8 & 0.00007 & 0.00018 & 0.00009 & 0.82243 & 0.00064 & 0.00401 & 0.00161 & 0.00353 & 0.00045 \\
\hline 9 & 0.00006 & 0.00017 & 0.00009 & 0.82294 & 0.00062 & 0.00399 & 0.00160 & 0.00357 & 0.00044 \\
\hline 10 & 0.00006 & 0.00017 & 0.00009 & 0.82306 & 0.00060 & 0.00401 & 0.00161 & 0.00359 & 0.00043 \\
\hline
\end{tabular}

Variance decomposition that shows the response of the return on various indices to changes in the MERVAL index, the response is measured over 10 periods. The years used to obtain the impulse response function are between 2001 and 2007, frequency is weekly. The indexes are SP500:U.S., ftse100:U.K., bovespa: Brazil, merval: Argentina, dax: Germany, cac40: France, smi: Switzerland, tsx: Canada, Nikkei225: Japan

Figure 4: Impulse response function, impulse is MERVAL

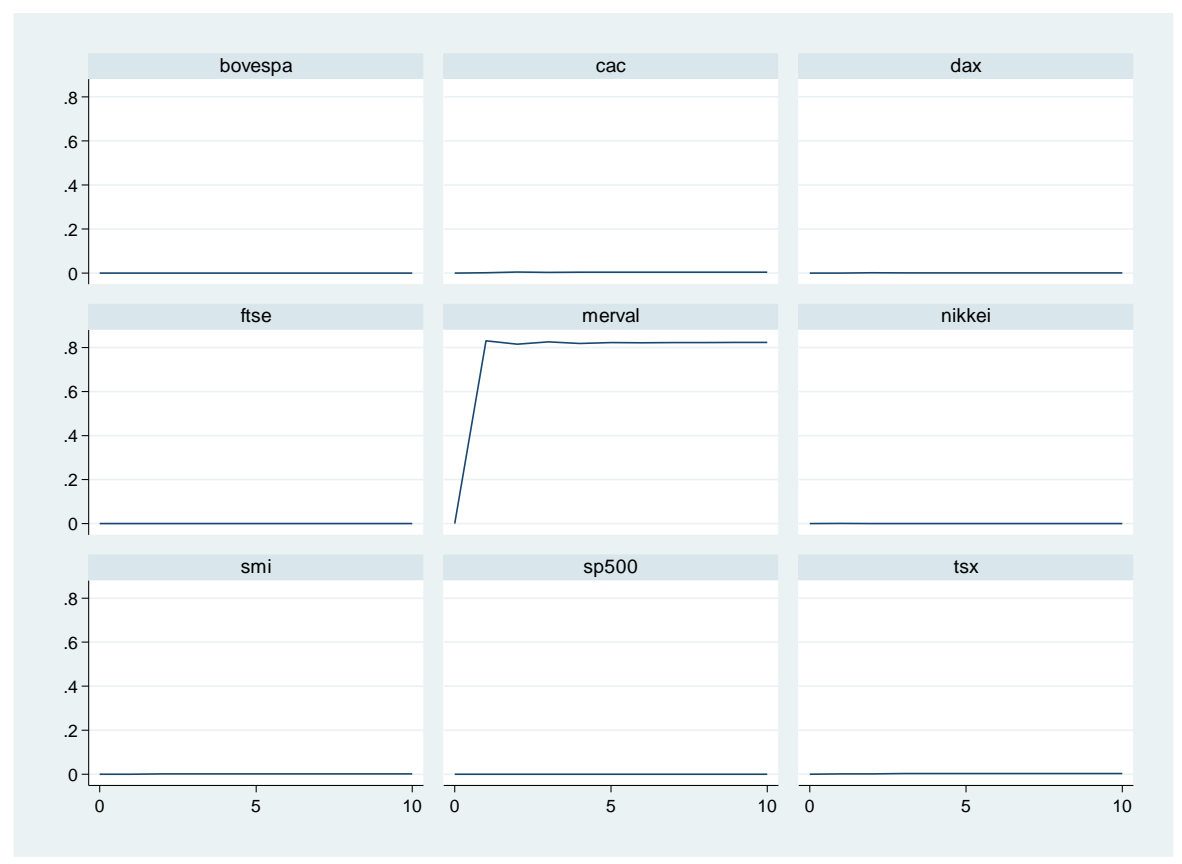

Impulse response functions for several markets considered in this study, the number of periods is ten, the frequency is weekly. The indexes are SP500:U.S., ftse100:U.K.., bovespa: Brazil, merval: Argentina, dax: Germany, cac40: France, smi: Switzerland, tsx: Canada, Nikkei225: Japan

Despite the proportion of the total foreign portfolio investment attributable to Japan, the NIKKEI does not explain more than $1 \%$ of the variation in non Japanese stock returns. 
Another feature observed is that the home index explains more than any of the other markets for all countries studied. From the model perspective, this is the result of home traders having information that is closer to the true value of the home asset than what foreign traders have, which implies that home traders invest more in home assets than foreign traders do.

Overall, the analysis of the data suggests that what is usually interpreted as one market influencing another is, at least partially, the result of cross border investment where informed traders in one market embed their information into the price of the asset in other country.

The model also suggests that industry commonality could result in a perception that a market leads another. The industry decomposition presented in the United Nations' GDP tables is well suited to study industry commonality across countries. Table 6 presents the proportion of several industries in the GDP for the countries used in this study.

From Table 6 we see that agriculture, fishing, and hunting (ISIC A-B) constitute above 7\% of the GDP for Argentina and Brazil, a proportion that is higher than for the other countries studied. This fact suggests that common information affecting these industries will be incorporated in both markets and can be interpreted as one market leading the other. Thus, in Table 4 we see that the variance in the BOVESPA index explains about 5\% of the variance of the MERVAL index. Table 5, to the contrary, shows that variations in the MERVAL index have very little effect on the variation of the BOVESPA index. Figure 3 shows the effect of an impulse originated in BOVESPA in the MERVAL index to be not negligible, supporting the idea of industry commonality leading to the conclusion that, in this case, the Brazilian market influences the Argentinean market in a variance decomposition / impulse response function study.

We can also see that mining, manufacturing, and utilities (ISIC E and D) constitute between 6.4 and 6.2 percent of the GDP for Canada and Argentina respectively, a higher proportion than for the other countries studied. According to the model, the commonality between mining, manufacturing, and utilities (ISIC C and E) industries in these countries can lead to the interpretation of one market leading another in a variance decomposition / impulse response function study. We can see in Table 5 that the variance in the MERVAL returns influences the Canadian market more than the rest of the markets used in this paper, except for France, suggesting that, as implied by the model, industry commonality can be interpreted as one market leading another.

Table 6: GDP decomposition by industry for the countries used in this study

\begin{tabular}{|l|c|c|c|c|c|c|c|c|c|}
\hline & U. S. & U.K. & France & Germany & Switzerland & Japan & Canada & Argentina & Brazil \\
\hline $\begin{array}{l}\text { Agriculture, hunting, forestry, fishing } \\
\text { (ISIC A-B) }\end{array}$ & 0.0197 & 0.0125 & 0.0308 & 0.0110 & 0.0198 & 0.0182 & 0.0200 & 0.0721 & 0.1144 \\
\hline $\begin{array}{l}\text { Mining, Manufacturing, Utilities } \\
\text { (ISIC C and E) }\end{array}$ & 0.0372 & 0.0358 & 0.0193 & 0.0255 & 0.0237 & 0.0298 & 0.0647 & 0.0624 & 0.0465 \\
\hline $\begin{array}{l}\text { Manufacturing } \\
\text { (ISIC D) }\end{array}$ & 0.1836 & 0.1673 & 0.1628 & 0.2255 & 0.2038 & 0.2531 & 0.1592 & 0.2634 & 0.2330 \\
\hline $\begin{array}{l}\text { Construction } \\
\text { (ISIC F) }\end{array}$ & 0.0355 & 0.0466 & 0.0409 & 0.0371 & 0.0572 & 0.0622 & 0.0526 & 0.0537 & 0.0639 \\
\hline $\begin{array}{l}\text { Wholesale, retail trade, restaurants and hotels } \\
\text { (ISIC G-H) }\end{array}$ & 0.2076 & 0.1337 & 0.1116 & 0.1082 & 0.1395 & 0.1456 & 0.1462 & 0.1540 & 0.0691 \\
\hline $\begin{array}{l}\text { Transport, storage and communication } \\
\text { (ISIC I) }\end{array}$ & 0.0759 & 0.0968 & 0.0708 & 0.0660 & 0.0700 & 0.0748 & 0.0746 & 0.0699 & 0.0529 \\
\hline Other Activities (ISIC J-P) & 0.4446 & 0.4296 & 0.4339 & 0.4487 & 0.4240 & 0.4598 & 0.4095 & 0.3505 & 0.4025 \\
\hline
\end{tabular}

GDP decomposition by industry according to the United Nations Statistical Database, average for the years 1997 to 2007 . The details of the classification ISIC can be found in the United Nations Statistical Division website, http://unstats.un.org/unsd/cr/registry/regcst.asp?Cl=2. 


\section{CONCLUSIONS}

Several papers claim that a given market leads another. The aim of this paper is to give substance to such claim by delving on the question of: what does it mean that "market A leads market B"? The comparison of the portfolio investment by the countries in this study with the variance decomposition / impulse response function of their stock markets returns suggest that, as implied by the model presented, information embedded by home traders into a foreign market can be interpreted as "market A leads market B". The comparison of the GDP decomposition for the countries used in this study with the results obtained in the variance decomposition / impulse response function analysis suggest that, as indicated by the model, industry commonality can also lead to the belief that market A leads market B. Overall, the results of one market leading another could be just an artifact that is reflecting cross border trading, or commonality of industries affected asynchronously by the same information.

\section{AUTHOR INFORMATION}

Paolo Miranda has a Bachelor in Mechanical Engineering, Master in Business Administration, and a Ph.D. in Finance. He has taught at the University of New Mexico and Purdue University Calumet and worked for years in the Engineering industry. His research interests are International Finance, Asset Pricing, and Corporate Governance.

\section{REFERENCES}

1. Arshanapali, B and John Doukas, 1993, International stock market linkages: Evidence from the pre- and post October 1987 period, Journal of Banking and Finance 17, pp. 193-208

2. Bessler, D. and Jian Yang, 2003, The structure of interdependence in international stock markets, Journal of International Money and Finance, 22, pp 261-287

3. Chen, G, Michael Firth, and Oliver Meng Rui, 2002, Stock market linkages: evidence from Latin America, Journal of Banking and Finance, 26, pp 1113-1141

4. Dwyer G. and R.W Hafer, 1988, Are national stock markets linked?, Federal Reserve Bank of St. Louis Review 70 (November/December 1988), pp. 3-14.

5. Eun, C. and Sangdal Shim, 1989, International transmission of stock market movements, Journal of Financial and Quantitative Analysis, 24, pp 241-256

6. Harvey Campbell and Geert Bekaert, 1995, Time varying world market integration, The Journal of Finance 50, pp 403-444

7. Liu, Y.A., Pan, M.S., and Shieh, J.C.P., 1998, International transmission of stock price movements: Evidence from the U.S. and five Asian Pacific markets, Journal of Economics and Finance, 22, pp 59-69

8. Andrew Lo and Craig MacKinlay, 1999, A Non Random Walk Down Wall Street, Princeton University Press, Princeton, NJ

9. Masish, A.M., and Masish, R., 2002, Propagative causal price transmission among international stock markets: evidence from the pre- and post globalization period, Global finance Journal, 13, pp 63-91

10. Phylaktis, K. and Ravazzolo, F., 2002, Stock market linkages in emerging markets: implications for international portfolio diversification, working paper, City University Business School

11. Roll, R., 1992, Industrial structure and the comparative behavior of stock market indexes, The Journal of Finance, 47, pp 3-41

12. Taylor, M. and Ian Tonks, 1989, The internationalization of stock markets and the abolition of U.K. exchange control, The Review of Economics and Statistics, 71, pp 332-336 